\title{
A COMPLEXIDADE E A COERÊNCIA VISUAL NA AGRADABILIDADE PERCEBIDA EM SALAS DE AULA PARA ENSINO SUPERIOR
}

\section{VISUAL COMPLEXITY AND COHERENCE ON THE PERCEIVED PLEASANTNESS IN HIGHER EDUCATION CLASSROOMS}

\author{
Patrícia Barbosa Acioli Novaes ${ }^{1}$, M.Sc. \\ Lourival Costa Filho ${ }^{2}$, D.Sc. \\ (1) Universidade Federal de Pernambuco - UFPE \\ patriciacioli@gmail.com \\ (2) Universidade Federal de Pernambuco - UFPE (NDC / PPGDesign / PPErgo) \\ lourivalcosta@yahoo.com
}

Salas de aula para ensino superior, Agradabilidade percebida, Ergonomia do ambiente construído. Objetiva-se avaliar a agradabilidade percebida em salas de aula para ensino superior. A Teoria das Facetas estruturou a investigação, que utilizou o questionário para coletar dados, a Análise da Estrutura de Similaridade (SSA) e uma tabela de distribuição de frequência para interpretá-los. Os resultados corroboram parcialmente com as sugestões teóricas.

Higher education classrooms, Perceived pleasantness, Ergonomics of the built environment. It aims to assess the perceived pleasantness in higher education classrooms. Facet Theory designed the empirical investigation, which used a questionnaire to collect data and the Similarity Structure Analysis (SAA) and the frequency distribution table to interpret them. The results partially corroborate the theoretical suggestions.

\section{Introdução}

Ao longo dos anos, cada vez mais estudantes têm tido acesso ao ensino superior, o que contribui para o aumento no número de Instituições de Ensino Superior (IESs) no país. Muitas vezes, esse aumento na quantidade de oferta por cursos de nível superior nos faz questionar o comprometimento com a qualidade do ensino e do aprendizado, mas também traz à tona indagações quanto à agradabilidade dos ambientes de ensino e aprendizagem nessas IESs.

Em 1951, Anísio Teixeira já afirmava que nenhum outro elemento é tão fundamental no complexo da situação educacional, depois do professor, quanto o prédio e suas instalações físicas. Podemos trazer essa percepção para a realidade dos ambientes de ensino superior, considerando que a sala de aula tem como finalidade dar suporte ao processo de formação do aluno, sendo de grande importância no processo de construção do aprendizado.

Segundo Guidalli (2012), com a vivência diária é natural que qualquer aluno da graduação ou professor conheça bem o ambiente de sala de aula.
No entanto, essa vivência tem sido desconsiderada na sua concepção, haja vista que vários problemas de ordem espacial causam desconforto - aos usuários de salas de aula teórica - em universidades.

Ressaltando a importância do projeto para os ambientes de ensino, pode-se destacar que, conforme Sanoff (2001), o ambiente de sala de aula contribui para a aprendizagem quando ele é cuidadosamente projetado e busca atender às necessidades de seus principais utilizadores, tanto de professores como de alunos.

Entende-se que as decisões projetuais para ambientes de salas de aula têm efeitos sobre as questões do ensino e aprendizagem, considerando que o espaço resultante do projeto será a interface que permitirá as trocas e proporcionará a adequação do ambiente, o que aponta para um enfoque nos domínios da ergonomia do ambiente construído.

No entanto, de acordo com Villarouco (2011), a ergonomia do ambiente extrapola as questões puramente arquitetônicas, focando seu 
PUC-Rio Pontifícia Universidade Católica do Rio de Janeiro Departamento de Artes \& Design | PPGDesign

posicionamento na adaptabilidade e conformidade do espaço às tarefas e atividades que neles serão desenvolvidas, mas também mediados pelo sentimento e percepção do usuário.

Com base nesse ponto de vista, os ambientes relacionam-se também com fenômenos de ordem psicológicos, portanto subjetivos, que se identificam com os atributos ambientais, podendo interferir no desempenho do usuário no ambiente e, mais especificamente destacando, na realização de suas tarefas e atividades.

Com foco na avaliação afetiva de ambientes, a investigação empírica realizada - estruturada a partir da Teoria das Facetas - foi delineada e tomou para estudo duas características dos atributos de salas de aula para ensino superior (facetas): complexidade e coerência, pelas suas possíveis influências na agradabilidade percebida nesse tipo de ambiente.

Apesar de pesquisadores da psicologia teorizarem sobre as influências das características visuais dos atributos ambientais sobre o afeto e a emoção humanos, as análises empíricas sobre a agradabilidade percebida em salas de aula para ensino superior, geralmente ficam para trás.

A partir desse contexto estratégico, visando estabelecer diretrizes para projetos do ambiente de ensino superior e revisar posturas para sua qualificação, este artigo objetiva prover informações empíricas sobre o efeito da complexidade e da coerência de salas de aula para ensino superior na agradabilidade percebida.

Certas características visuais do ambiente podem ter particular relevância para a resposta avaliativa (afeto, resposta psicológica, comportamento), incluindo, por exemplo, complexidade e coerência, selecionadas para a abordagem aqui proposta. Para sua aplicação na metodologia de projeto de ambientes, entretanto, é importante identificar se elas são determinantes para a percepção e a avaliação do usuário que frequenta o tipo de espaço enfocado na pesquisa pretendida.

Apesar de essas respostas avaliativas, por si só, não poderem prever o comportamento real do usuário, a avaliação combinada de respostas avaliativas e do comportamento previsto dá uma boa indicação do comportamento real (NASAR, 1988). Assim, na presente pesquisa, os respondentes foram solicitados $\mathrm{a}$ indicar em que medida gostariam de estar $\mathrm{e}$ permanecer em várias salas de aula para ensino superior, com diferentes níveis de complexidade e de coerência, instrução de pesquisa que pode ser tomada como uma expressão da agradabilidade percebida, nesse tipo de local pela amostra populacional abordada nesta pesquisa.

Do ponto de vista da sua importância para a metodologia ergonômica do ambiente construído, esta pesquisa se justifica - para o ergodesign de ambientes - por poder contribuir com informações norteadoras à elaboração de projetos de ambientes e, por conseguinte, em um sentido mais amplo, favorecer a qualidade visual percebida em salas de aula para ensino superior, as necessidades afetivas de seus usuários, uma vez que, o fazer projetual não pode estar resumido ao ato de projetar um edifício ou ambiente que, simplesmente, esteja adequado do ponto de vista prático-funcional.

Assim, como alertou Rykwert (2004), arquitetos por muito tempo, contentaram se em ser vistos como pessoas de bom gosto, para se transformar - nos meados do século XX - em gerentes e especialistas que fazem os edifícios funcionar, e depois acrescentam o componente estético.

Por isso, a abordagem ergonômica da presente pesquisa - que se propõe a contribuir com a fase de concepção de projetos - considera necessário o entendimento de que o ambiente construído influencia o comportamento humano, de modo que as pessoas estão mais propensas a frequentar ambientes percebidos favoravelmente e evitar outros que julguem negativos.

\section{Considerações Teóricas}

Quando se pensa em salas de aula, a imagem que costuma vir à mente são as tradicionais salas com carteiras enfileiradas de frente para a lousa. Essa imagem não está apenas no repertório de muitos indivíduos que passaram pelas carteiras escolares, mas permanece no imaginário de quem frequentou também o ensino superior (grupo populacional considerado nesta pesquisa).

Nos dias atuais, com o aumento da demanda escolar e também da oferta de cursos em Instituições de Ensino Superior, a arquitetura para esse tipo de instituição tornou-se bastante padronizada, desde os projetos de arquitetura escolar, como é o caso das escolas padrão do Fundo Nacional de 
PUC-Rio Pontifícia Universidade Católica do Rio de Janeiro Departamento de Artes \& Design | PPGDesign

Desenvolvimento da Educação (FNDE), até Instituições de Ensino Superior particulares, onde a padronização também tornou-se uma prática comum, com um partido arquitetônico voltado à racionalidade construtiva, privilegiando a funcionalidade, seguindo critérios puramente econômicos e focados na rapidez da execução, fatores que convergem para a presença de muitos prejuízos em seus resultados.

Fernández-Ramírez, Rebolloso e Cantón (2007) afirmam, baseados em resultados de pesquisas anteriores, que a qualidade da sala de aula está relacionada à sua legibilidade, à ausência de conflitos sinergéticos (a estimulação excessiva, os ruídos e a falta de privacidade visual ou vistas de janela que tirem a atenção do aluno), e a condições básicas de conforto ambiental.

A ergonomia, como a tecnologia projetual das comunicações entre humanos e máquinas, trabalho e ambiente (MORAES; MONT'ALVÃO, 2009), está interessada em contribuir com pesquisas que possam edificar seu corpo de conhecimento sobre novas diretrizes de projeto para ambientes de trabalho, em prol da melhoria da interface entre esses espaços e seus utilizadores.

Com esse propósito, é importante criar bases objetivas para decisões de projeto para espaços de salas de aula para ensino superior e, a partir deste ponto, este artigo trará algumas sugestões teóricas da psicologia que embasam a preferência ambiental e sua avaliação, com o propósito principal de apoiar as discussões dos resultados empíricos desta pesquisa, e, posteriormente, de favorecer a melhoria das condições do ambiente a favor do usuário.

É importante ressaltar que a sala de aula é um ambiente físico dinâmico, necessitando de elementos arquitetônicos que capacitem a reestruturação de seu espaço, a fim de alcançar os objetivos propostos. Sua identidade deve refletir o repertório de seus usuários, seus pensamentos, suas memórias e ações. Uma sala sem identidade é inexpressiva, amorfa e traduz um ensino pobre (GUIDALLI, 2012).

A discussão acima, contudo, não deve ser considerada de uma maneira simplista, na medida em que o sentido humano tem uma capacidade limitada de assimilação de estímulos por unidade de tempo. Por essa razão, o receptor escolhe aspectos essenciais da oferta de estímulos e, por conseguinte, a oferta suficiente de informação é um aspecto essencial no campo da percepção e do julgamento ambiental.

Para prosseguir, é importante lembrar que Kaplan e Kaplan (1989) definem o julgamento ambiental como produto de dois processos relacionados com a sobrevivência humana: "envolvimento" e "fazer sentido", já que um ambiente deve ser envolvente para atrair a atenção e fazer sentido a fim de que se possa operar nele. A complexidade e a coerência são características ambientais visuais relevantes, respectivamente relacionadas com esses processos.

A complexidade diz respeito à diversidade dos elementos presentes na cena e a distinção entre eles. É sugerido que pouca complexidade é monótona e muita é estressante. O nível intermediário é, possivelmente, o mais agradável (BERLYNE,1972; WOHLWILL, 1976; NASAR, 2000).

A coerência, variável da categoria de ordem, é definida como o grau em que a cena se encaixa, incluindo fatores que facilitam a organização do plano da imagem, sua compreensão e estruturação, podendo reduzir a incerteza e aumentar o tom hedônico (beleza ou agradabilidade) da cena (KAPLAN; KAPLAN, 1989).

Apesar de a qualidade visual percebida depender, em parte, de fatores perceptivos/cognitivos, ela é, por definição, um julgamento emocional que envolve avaliação e sentimentos (NASAR, 1988). Como resultado, a agradabilidade percebida foi medida aqui através de julgamentos avaliativos para cenas de salas de aula, para ensino superior, escolhidas a partir da manipulação sistemática das características visuais de complexidade e de coerência da cena, essa última avaliada aqui, através de uma covariável, qual seja: o contraste.

Esse referencial teórico que foi exposto acima, proposto em Kaplan e Kaplan (1982), a partir de Kaplan (1988), tem particular relevância nesta pesquisa, assim como as evidências empíricas determinadas por Ward e Russell (1981), conforme apresentado em Russell (1988), que tratam das avaliações afetivas de lugares.

Para serem relevantes, as avaliações afetivas devem centrar-se nas dimensões descritoras que as pessoas realmente usam para avaliar os lugares. Utilizando uma variedade de estratégias de pesquisa, os 
PUC-Rio Pontifícia Universidade Católica do Rio de Janeiro Departamento de Artes \& Design | PPGDesign

psicólogos James Ward e Larry Russell encontraram quatro dimensões afetivas notáveis para os ambientes: agradável (pleasant), estimulante (arousing), excitante (exciting), relaxante (relaxing). A agradabilidade é uma dimensão puramente avaliativa; enquanto o estímulo independe da dimensão avaliativa. A excitação e o relaxamento envolvem misturas de avaliação e de estímulo. Desse modo, as pessoas experienciam lugares excitantes como mais agradáveis e mais estimulantes do que os entediantes; e experienciam lugares relaxantes como mais agradáveis e menos estimulantes do que os angustiantes.

Baseando-se nos achados de Ward e Russell (1981), relacionados com os descritores da qualidade afetiva, esta pesquisa pretende avaliar a agradabilidade percebida em várias cenas de salas de aula para ensino superior, com diferentes qualidades estéticas.

Buscando sumarizar as evidências empíricas expostas, e sua aplicação nesta pesquisa, cumpre destacar que, em relação ao efeito da complexidade nas respostas avaliativas para o ambiente, é sugerido que a agradabilidade seja significativamente maior para cenas com complexidade média do que para aquelas com complexidade mínima ou máxima (NASAR, 2008). Já em relação aos efeitos da coerência (obtida através da redução do contraste) nas respostas avaliativas para o ambiente, também conforme Nasar (2008), é sugerido que a agradabilidade seria maior para cenas com coerência alta (contraste baixo), moderada para cenas com coerência média (contraste médio) e menor para cenas com coerência baixa (contraste alto).

\section{Considerações Teórico-Metodológicas}

A Teoria das Facetas (TF), procedimento metodológico criado e desenvolvido por Louis Guttman, foi adotada no desenho da investigação empírica. Seu uso envolve a identificação dos diferentes conceitos que delineiam a pesquisa e consiste em estabelecer hipóteses, encontrar as facetas do modelo teórico e definir os elementos que as constituem.

A TF estrutura o delineamento da pesquisa em uma sentença semântica que relaciona os elementos teóricos e empíricos identificados com seus possíveis resultados (SOLOMON, 2019). Essa sentença estruturadora normalmente reúne três tipos básicos de facetas que representam objetos e/ou variáveis da investigação empírica. Cada faceta é constituída por elementos internos que relacionam de forma exclusiva e abrangente o universo de cada componente da pesquisa.

De modo geral, de acordo com Bilsky (2003) e Shye at al. (1994), há três tipos de básicos de facetas. O primeiro tipo define a população da pesquisa e seus eventuais grupos de interesse (faceta de população). O segundo tipo diz respeito ao conteúdo das variáveis estudadas (faceta de conteúdo). As facetas de conteúdo juntamente com a faceta de população representam o domínio da pesquisa. $\mathrm{O}$ terceiro tipo de faceta consiste no universo de reações ou possibilidade de respostas dos sujeitos em relação às variáveis representadas nas facetas de conteúdo (faceta de racional).

Pesquisas demonstram, segundo Monteiro e Loureiro (1994, apud COSTA FILHO, 2014), que há, normalmente, três facetas básicas para a avaliação de lugares e cada uma delas representa um componente da experiencia com o local a ser investigado: foco, referente e nível. A faceta do foco é produto de uma constatação psicológica empírica que as pessoas respondem de modo diverso a questões de cunho geral, das específicas. Determina, no caso da avaliação de lugares, que existem elementos que são centrais ou essenciais na experiência de um lugar, e outros que são periféricos ou específicos. Assim, por exemplo, uma atividade pode ser executada em qualquer ambiente da casa (foco geral); já outras ocorrem em um determinado cômodo (foco específico). A faceta do referente da experiência define os diferentes aspectos considerados pelas pessoas nas suas avaliações. Um escritório, por exemplo, pode ser avaliado pelo referente físico ou organizacional. A faceta do nível considera a escala ambiental, que influi na avaliação de uso dos espaços. Há, por exemplo, situações em que o bairro exerce influência sobre a avaliação residencial, mas o contrário também é verdadeiro.

A partir dessas considerações, foi formulada a sentença estruturadora para a avaliação da agradabilidade percebida em salas de aula para ensino superior (Quadro 01 - na página seguinte), que reflete as relações entre os elementos internos das facetas do referente da experiência (o foco e o nível da experiência não variam), sendo precisamente essas relações que serão testadas na 


\section{Ergodesign \& HCI}

número especial, volume 7, ano 7 (2019)

ISSN 2317-8876, Rio de Janeiro - Brasil

situação empírica, através de imagens/cenas de salas

\begin{tabular}{|c|c|c|}
\hline \multicolumn{3}{|c|}{ Em que medida a pessoa $(\mathbf{x})$ avalia que as caracteristicas visuais de } \\
\hline $\begin{array}{l}\text { (FACETAA) - referente } \\
\text { COMPLEXIDADE } \\
\text { (A1) complexidade mínima } \\
\text { (A1) complexidade modera } \\
\text { (A1) complexidade máxima }\end{array}$ & $\begin{array}{l} \\
a \\
a \\
\text { a }\end{array}$ & $\begin{array}{l}\text { (FACETA B) - referente } \\
\text { CONTRASTE } \\
\text { (B1) contraste baixo } \\
\text { (B1) contraste médio } \\
\text { (B1) contraste alto }\end{array}$ \\
\hline $\begin{array}{l}\text { (RACIONAL) } \\
\text { (1) nada } \\
\text { (2) pouco } \\
\text { (3) mais ou menos } \\
\text { (4) muito } \\
\text { (5) demais }\end{array}$ & $\begin{array}{l}\text { estar e permanecer em sala de aula do ensino superior } \\
\text { (expressão da agradabilidade percebida) }\end{array}$ & $\begin{array}{l}\text { anecer em sala de aula do ensino superior } \\
\text { a agradabilidade percebida) }\end{array}$ \\
\hline
\end{tabular}

de aula para ensino superior.

Quadro 01 - Sentença Estruturadora para a avaliação da agradabilidade percebida em sala de aula do ensino superior

Nessa sentença estruturadora para a avaliação da agradabilidade percebida em sala de aula para ensino superior, os elementos internos das variáveis complexidade e contraste podem ser organizados de forma semelhante a uma análise combinatória, produzindo nove diferentes conjuntos ou situações $(\mathrm{A} 3 \times \mathrm{B} 3=\mathrm{AB} 9)$ a serem avaliados empiricamente.

A sentença estruturadora atua como uma suposição inicial da pesquisa e, segundo Costa Filho et al. (2016), deve ser analisada em relação aos resultados empíricos encontrados, ao final da pesquisa, que devem corroborar ou contestar esse modelo conceitual de avaliação. Após esse processo, as informações promovidas devem ou não servir de base para construção de uma nova sentença.

\section{CONSIDERAÇÕES METODOLÓGICAS}

A investigação empírica realizada - classificada como do tipo exploratória e sem o emprego de amostragem probabilista (MARCONI; LAKATOS, 2002) - utilizou um questionário online, elaborado com o auxílio do Google Forms e baseado no Sistema de Classificações Múltiplas, como método de procedimento para coletar os dados.

O Sistema de Classificações Múltiplas, adaptado por Canter, Brown e Groat (1985), consiste em pedir aos participantes para classificar os mesmos elementos diversas vezes, através de critérios estabelecidos por eles próprios (classificações livres) ou pelo pesquisador (classificações dirigidas), para entender suas ideias sobre eles. Os elementos utilizados, portanto, devem ser agrupados pelas similaridades de forma que aqueles de uma mesma categoria tenham algo importante e distinto das demais.
PUC-Rio Pontifícia Universidade Católica do Rio de Janeiro Departamento de Artes \& Design | PPGDesign

LEUI | Laboratório de Ergodesign e Usabilidade de Interfaces

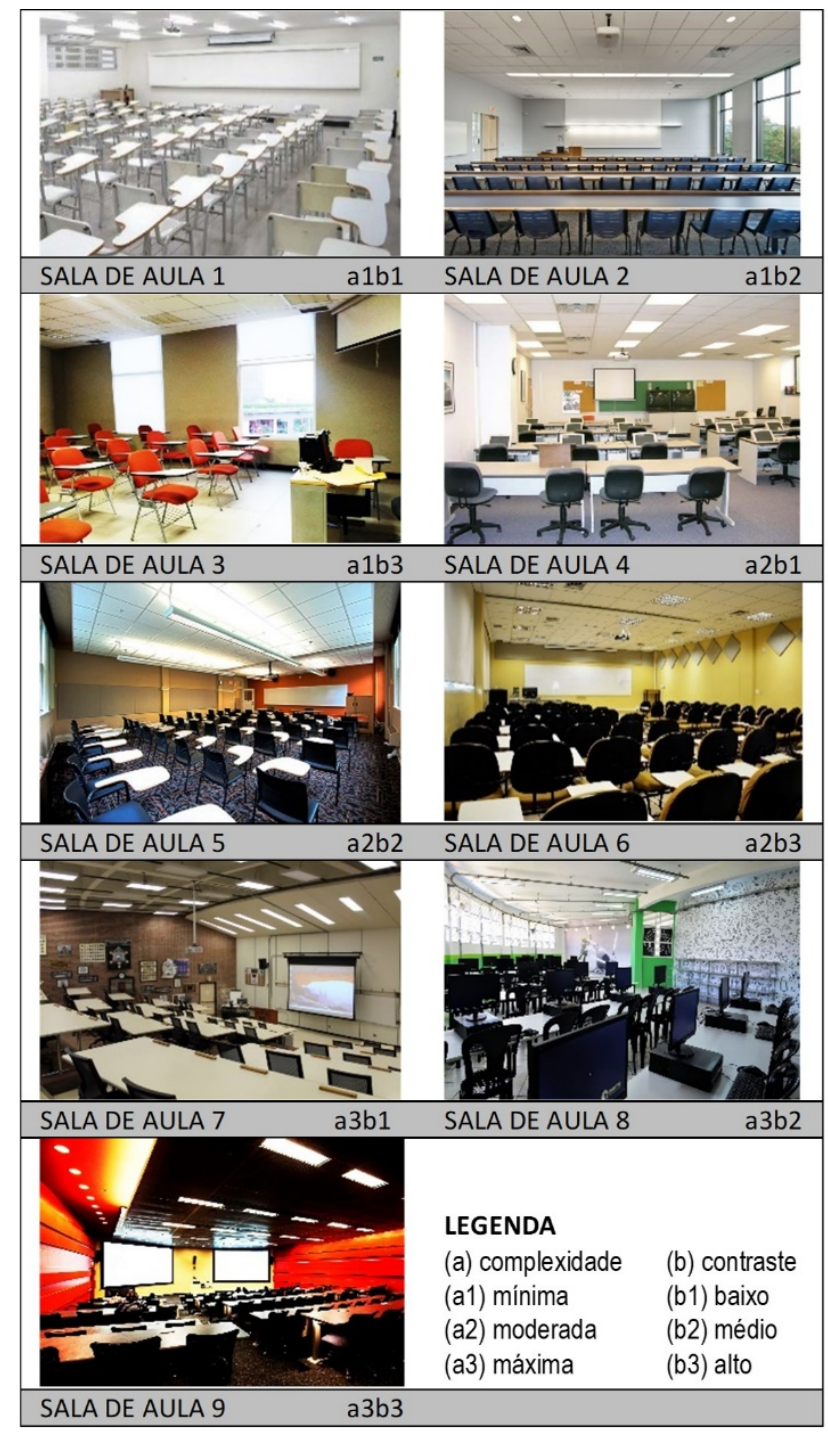

Quadro 02 - Salas de aula para ensino superior representando as relações de complexidade e de contraste

No questionário online foram apresentadas cenas de salas de aulas para ensino superior, obtidas no Google Imagem e, posteriormente, validadas por um grupo de três alunos do Programa de Pós-Graduação em Ergonomia (PPErgo/UFPE), que funcionaram como juízes, de modo a se obter o consenso sobre três diferentes níveis de complexidade e contraste percebidos nas cenas. Tomou-se também o cuidado de procurar imagens sem pessoas, com o propósito de controlar o nível de complexidade nas cenas.

As cenas das nove salas de aulas para o ensino superior - apresentadas como elementos de estímulo no questionário - estão diretamente relacionada às variáveis desta pesquisa, listadas na sentença estruturadora para a avaliação da agradabilidade percebida nesse tipo de ambiente, representando a 
manipulação sistemática de três diferentes níveis de complexidade e contraste (Quadro 02).

Depois de elaborado, o questionário online foi divulgado através das redes sociais, e a escolha dessa ferramenta se deu pela praticidade de coleta e conveniência de ser um meio de se conseguir maior retorno, em um curto período de tempo, além de permitir o uso de imagens.

Quanto às instruções de pesquisa, logo de início, no sentido de resguardar o consentimento livre e desimpedido de participação, o questionário informava que: (i) o estudo objetivava a avaliação visual de salas de aula do ensino superior; (ii) não havia respostas certas ou erradas, importando apenas a opinião de cada um; (iii) os dados obtidos teriam apenas fins acadêmicos; (iv) era garantido o anonimato; (iv) era possível interromper a pesquisa em qualquer momento.

Após as informações introdutórias sobre o perfil do participante, era pedido que este indicasse em que medida cada uma das nove cenas favoreciam estar e permanecer nelas. Como universo de respostas, foram ofertados cinco diferentes níveis, que iam de "nada" (mínimo favorecimento) até "demais" (máximo favorecimento).

De modo a desenvolver uma correspondência entre o sistema de definição conceitual proporcionado pela sentença estruturadora e as observações empíricas, classicamente a Teoria das Facetas faz uso de programas computacionais que aplicam técnicas de escalonamento multidimensional que, em geral, objetiva sistematizar e descobrir uma estrutura oculta nos dados. Entre as técnicas mais associadas às análises das facetas, destaca-se a Análise da Estrutura de Similaridades (Similarity Structure Analysis - SSA), utilizada para interpretar os dados empíricos obtidos nesta pesquisa.

A SSA, para Roazzi, Monteiro e Rullo (2009), é um sistema de escalonamento multidimensional concebido para analisar a matriz de correlações entre " $n$ " variáveis representadas graficamente como pontos, em um espaço euclidiano. O sistema fundamenta-se no princípio da contiguidade que, como tal, traduz as relações de similaridades entre itens configurados pelas distâncias entre os pontos. Isso significa que a proximidade das variáveis no espaço multidimensional é proporcional ao grau de correlação que apresentam. Essas relações de similaridades podem formar regiões de contiguidade que possibilitam verificar se as hipóteses iniciais são transformadas em hipóteses regionais, em relação às quais se espera evidenciar regiões que abarquem aos elementos internos de cada faceta.

De acordo com a Teoria das Facetas, a base lógica para as várias hipóteses regionais considera a ordem entre os elementos de cada faceta. Uma faceta ordenada apresenta elementos em ordem hierárquica e pode ter um papel axial ou modular, dependendo da relação entre as demais facetas da sentença estruturadora. Se não tem relação com outras facetas, a faceta ordenada se apresentará de modo axial, ou seja, seus elementos se manifestam em sucessão linear, separados por linhas paralelas. Caso se encontre relacionada com uma ou mais facetas, seus elementos se manifestam de forma modular, ou seja, como formas circulares concêntricas. Nesse caso, as variáveis representadas por pontos, na forma circular central, têm um sentido mais geral que aquelas que estão localizadas próximas à borda, bem como as correlações das variáveis resultarão mais altas. Além das facetas ordenadas, existem outras cujos elementos se diferenciam de modo qualitativo, mas sem ordem óbvia. Essas facetas têm um papel polar, ou seja, seus elementos se reúnem em regiões cuneiformes com limites partindo de uma origem comum (COSTA FILHO, 2014).

O reconhecimento desses padrões de divisões - no espaço multidimensional de uma SSA - é importante para testar as hipóteses iniciais sobre os elementos das facetas na composição interna do conceito investigado. Isso é operacionalizado verificando se os construtos conceituais de uma dada faceta são realmente apropriados à estrutura empírica do conceito, bem como se estão inter-relacionados ou ordenados como previsto nas hipóteses.

\section{CONSIDERAÇÕES EMPÍRICAS}

Ao final da pesquisa, contou-se com a participação de 20 respondentes com nível de escolaridade superior completo (condição de inclusão) e idade entre 29 e 56 anos, sendo a maioria deles formada por mulheres (15), com idade entre 29 e 43 anos.

Os dados obtidos, relacionados à pesquisa online, foram tabulados em uma planilha do Microsoft Office Excel, com a finalidade de anotar a escala de intensidade que cada uma das nove cenas de salas de aula para o ensino superior recebeu de cada 
participante. Esses dados brutos alimentaram o HUDAP (Hebrew University Data Analysis

Package) com as informações necessárias para iniciar seu processamento no SSA, e verificar o efeito da complexidade e da coerência na agradabilidade percebida nesse tipo de ambiente.

Assim, a matriz gerada pela SSA, representando os coeficientes de correlação para as nove cenas de salas de aula para o ensino superior, utilizadas para a avaliação da agradabilidade percebida, baseia-se nos escores atribuídos pelos 20 participantes da pesquisa a cada uma dessas cenas.

Os coeficientes de correlação indicam a similaridade entre os itens da matriz. Os itens 01 e 03 , com 0.88 de correlação, mostraram-se os mais similares. A correlação mais negativa, com -0.66 de

dissimilaridade, foi observada entre os itens 02 e 09 . Quanto maior o coeficiente de similaridade entre dois itens, menor será a distância entre eles no diagrama do espaço geométrico da SSA.

O diagrama do espaço da SSA para a matriz de inter-relações, entre os nove itens ou cenas usadas para a avaliação da agradabilidade percebida em salas de aula para ensino superior, demonstra os testes de cada uma das facetas consideradas na pesquisa - complexidade, contraste - sobre essa distribuição espacial ou diagrama original.

Para testar cada faceta sobre o diagrama do espaço da SSA, as nove cenas receberam cores a partir do seu pertencimento a um dado elemento interno das facetas. Em seguida, verificou-se a existência de padrões de contiguidade regional, ou seja, padrões reconhecíveis de divisão do diagrama em regiões formadas por cenas de um mesmo elemento interno da faceta considerada. Esses diagramas têm as mesmas informações da matriz estatística, mas permitem assimilar com mais facilidade as correlações entre todos os itens ou cenas simultaneamente.

Os resultados dos diagramas da SSA revelaram que ambas as duas facetas testadas - complexidade e contraste - formam estruturas regionais de contiguidade entre os itens de um mesmo elemento interno, confirmando a aderência de ambas para a avaliação da agradabilidade percebida em salas de aula para o ensino superior, respondendo a uma questão da pesquisa.
Através dos diagramas da SSA para as Facetas A e $\mathrm{B}$ - complexidade e contraste - nota-se que os participantes captaram essas duas categorias, uma vez que formam regiões de similaridades. Também é possível verificar que os dois diagramas da SSA mostram formas circulares que dividem cada um deles em três regiões distintas (Figuras 01 e 02).

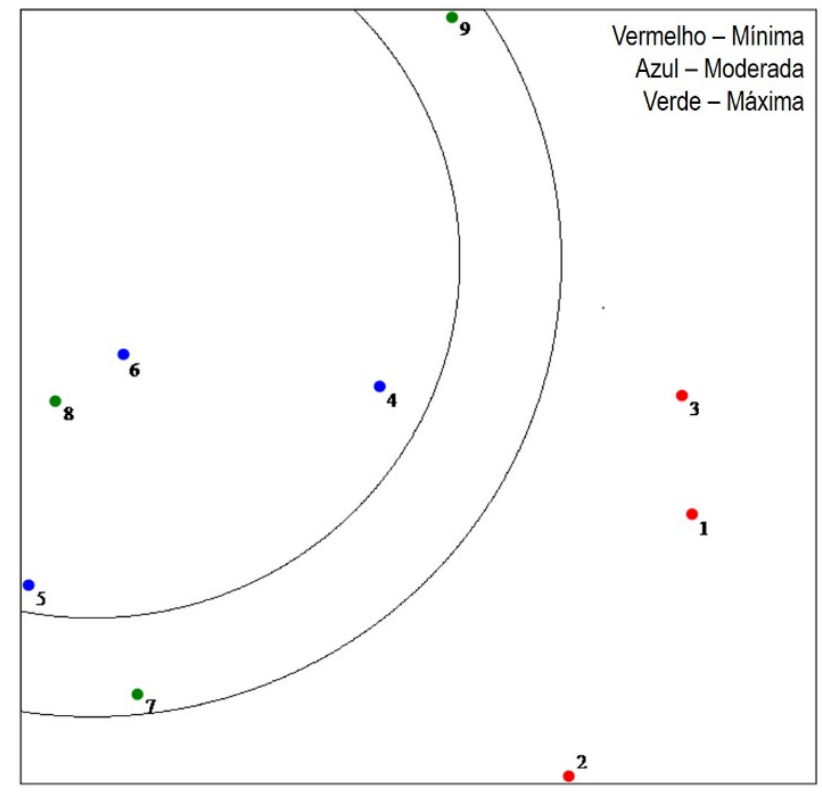

Figura 01: Diagrama do espaço da SSA com o teste para a FACETA A (COMPLEXIDADE)

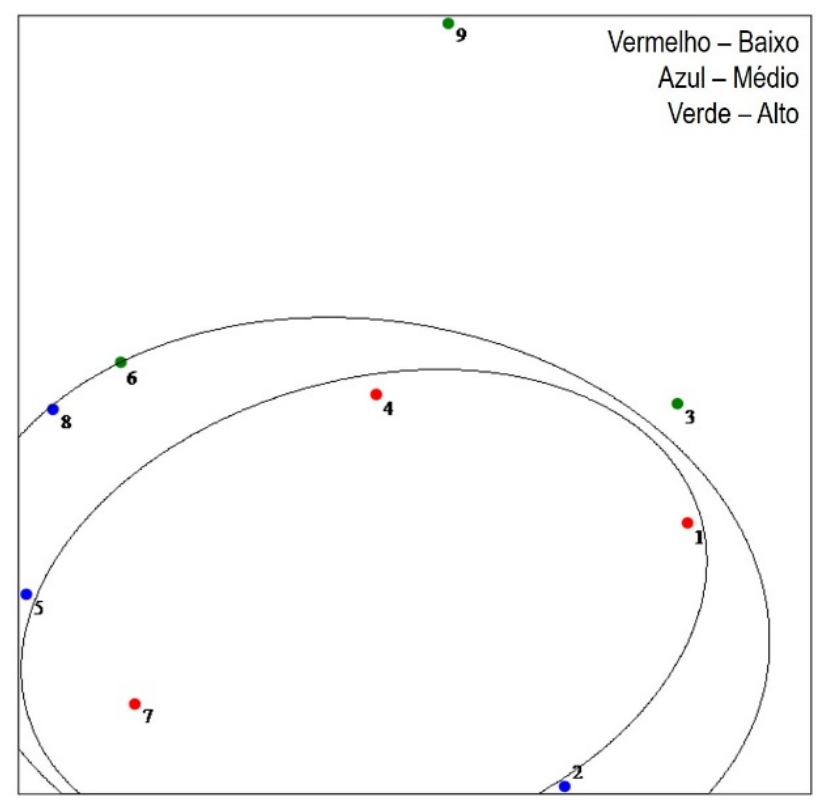

Figura 02: Diagrama do espaço da SSA com o teste para a FACETA B (CONTRASTE)

Os resultados merecem atenção especial, pois o padrão de divisão denota que as duas categorias 
PUC-Rio Pontifícia Universidade Católica do Rio de Janeiro Departamento de Artes \& Design | PPGDesign

(facetas) têm forte influência para a avaliação da agradabilidade percebida em cenas de salas de aula para ensino superior. As duas facetas desempenham um papel "modular" nos mapas plotados pela SSA, padrão em que os itens representados na parte central das formas circulares (complexidade moderada e contraste baixo) têm um caráter mais geral e regulador para a avaliação sugerida, do que aqueles das regiões periféricas, que correspondem aos aspectos específicos relacionados com o descritor da qualidade afetiva investigada (agradabilidade).

Esses resultados ainda sugerem que os participantes da pesquisa são mais influenciados pelas cenas de salas de aula para ensino superior com complexidade moderada e contraste baixo (coerência alta) nas avaliações da agradabilidade percebida nesse tipo de ambiente.

Explorando a projeção da Faceta A, complexidade, nota-se uma exceção na região circular central. A cena 8 , como mostra a Figura 01, definida inicialmente como uma sala de aula do ensino superior com complexidade máxima, foi captada pelos participantes como tendo um nível moderado.

Esse desvio pode ser justificado pelo fato de os atributos visuais que, hipoteticamente, definem a complexidade máxima sejam semelhantes entre si, como, por exemplo, cadeiras, mesas, computadores e luminárias. Isso, contudo, não invalida os resultados, já que os participantes captaram tanto a complexidade das cenas como seus três níveis na avaliação da agradabilidade percebida no tipo de ambiente enfocado.

Os resultados obtidos através da SSA, que, em geral, objetiva sistematizar e descobrir uma estrutura oculta nos dados, possibilitaram verificar que a representação gráfica dos dados empíricos tem uma estrutura que corresponde àquela sugerida pela teoria, ou seja, validaram o marco de referência formal de que cenas com complexidade moderada e contraste baixo (coerência alta) influenciam a agradabilidade percebida em ambientes.

Em prol de ampliar a aplicabilidade dos resultados na metodologia de projetos, os dados obtidos ainda foram interpretados a partir da tabela de distribuição das frequências dos dados inicialmente tabulados, considerando-se a soma dos escores atribuídos por todos os participantes da pesquisa para as nove cenas de salas de aulas do ensino superior avaliadas (Tabela 01). Nesse segundo momento, buscou-se principalmente identificar os níveis integrados de complexidade e de contraste que aumentam e diminuem a agradabilidade percebida em cenas de salas de aula para ensino superior.

\begin{tabular}{l|c|c|c|c|c|c|c|c|c} 
& C1 & C2 & C3 & C4 & C5 & C6 & C7 & C8 & C9 \\
\hline nada & $20 \%$ & - & $5 \%$ & $5 \%$ & $10 \%$ & $15 \%$ & $5 \%$ & $20 \%$ & - \\
\hline pouco & $25 \%$ & $35 \%$ & $5 \%$ & $30 \%$ & $20 \%$ & $55 \%$ & $25 \%$ & $25 \%$ & $30 \%$ \\
\hline médio & $25 \%$ & $35 \%$ & $65 \%$ & $35 \%$ & $30 \%$ & $10 \%$ & $30 \%$ & $30 \%$ & $20 \%$ \\
\hline muito & $30 \%$ & $15 \%$ & 155 & $20 \%$ & $30 \%$ & $20 \%$ & $25 \%$ & $20 \%$ & $45 \%$ \\
\hline demais & - & $15 \%$ & $15 \%$ & $10 \%$ & $10 \%$ & - & $15 \%$ & $5 \%$ & $5 \%$ \\
\hline
\end{tabular}

Tabela 01: Distribuição da frequência dos dados obtidos

Os dados mostrados na Tabela 01, de uma maneira geral, omitem o efeito esperado da complexidade e do contraste nas respostas avaliativas para a agradabilidade percebida em ambientes.

A cena de número 09 , sala de aula para o ensino superior com complexidade máxima e contraste alto (coerência baixa), foi percebida pelos respondentes como a MAIS agradável; enquanto a cena de número 06 , com complexidade moderada e contraste alto (coerência baixa), em um sentido oposto, foi percebida como a MENOS agradável (Figura 03).

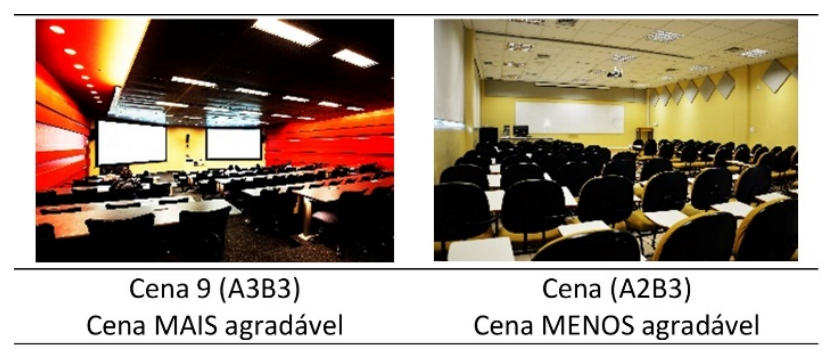

Figura 03 - Agradabilidade percebida em cenas de salas de aula para ensino superior (Fonte: Google Imagem)

Pelo viés teórico, conforme apresentado nas considerações teóricas deste artigo, em relação ao efeito da complexidade nas respostas afetivas para o ambiente, é sugerido que a agradabilidade aumenta para cenas com complexidade moderada, uma vez que a complexidade mínima é sugerida como monótona e entediante; já a complexidade máxima seria caótica e estressante. Quanto aos efeitos da coerência (obtida através da redução do contraste), é sugerido que a agradabilidade aumenta para cenas com contraste baixo, que eleva a coerência e favorece a compreensão de lugares. 
PUC-Rio Pontifícia Universidade Católica do Rio de Janeiro Departamento de Artes \& Design | PPGDesign

LEUI | Laboratório de Ergodesign e Usabilidade de Interfaces

Esses últimos resultados empíricos, divergindo das predições teóricas expostas no parágrafo acima, destoam do que é sugerido para a agradabilidade percebida em ambientes.

\section{CONCLUSÃO}

A avaliação da agradabilidade percebida em salas de aula para ensino superior tem importância e justifica-se para a ergonomia do ambiente construído, por criar uma base objetiva para decisões projetuais que envolvam a qualidade afetiva da agradabilidade.

Conforme demonstrado, através do auxílio da Teoria das Facetas, as características visuais dos atributos ambientais selecionadas para a avaliação da agradabilidade em salas de aula para ensino superior - complexidade e contraste - mostraram-se consistentes à estrutura do modelo conceitual definido para a avaliação realizada (sentença estruturadora para a avaliação enfocada).

Os resultados obtidos através dos diagramas geométricos do espaço da SSA, corroborando com o marco de referência teórica, apuraram empiricamente que a cena de sala de aula para ensino superior com complexidade moderada e contraste baixo (coerência alta) influencia a avaliação da agradabilidade percebida.

Buscando ampliar os resultados, a partir da tabela de distribuição das frequências dos dados obtidos, ainda se apurou que a cena com complexidade máxima e contraste alto (coerência baixa) aumenta a agradabilidade percebida, destoando do postulado teórico para a agradabilidade ambiental percebida.

Destaca-se, que a sala de aula para o ensino superior deve ser um local dinâmico, que requer metodologias ergonômicas de projetos que acompanhem essa dinamicidade, para poder refletir as necessidades afetivas de seus usuários, como a agradabilidade percebida.

\section{REFERÊNCIAS}

BERLYNE, D. E. Ends and meanings of experimental aesthetics. Canadian Journal of Psychology, Ottawa-Ontario, v. 26, 1972.

BILKSY, W. A. Teoria das Facetas: noções básicas.
Estudos de Psicologia, Campinas-SP, v.8, n.3, p. 357-365, 2003.

CANTER, D.; BROWN, J.; GROAT, L. Multiple Sorting Procedure for study conceptual systems. In CANTER, D.; BROWN, J.; BRENNER, M. (Eds.). Research Interview: use and approaches. London: John Wiley, 1985.

COSTA FILHO, L. O enfoque da teoria das facetas na avaliação de lugares. In: V ENCONTRO NACIONAL DE ERGONOMIA DO AMBIENTE CONSTRUÍDO \& VI SEMINÁRIO NACIONAL DE ACESSIBILIDADE INTEGRAL, 2014, Rio de Janeiro. Anais...Rio de Janeiro: PUC-Rio, 2014.

COSTA FILHO, L. L.; OLIVEIRA, I. F.; YOKOYAMA, S. A. A qualidade percebida da paisagem midiática do comércio varejista de Caruaru. In: MONT'ALVÃO, C.; VILLAROUCO, V. (Orgs.). Um novo olhar para o projeto: 3: a ergonomia no ambiente construído. Recife: Editora UFPE, 2016. p. 183-207.

FERNÁNDEZ-RAMÍREZ, B; REBOLLOSO, E; CANTÓN, P. The Nominal Group Technique and the environmental evaluation of university classrooms. Medio Ambiente y Comportamiento Humano, España, v. 8, n. 1-2, p. 49-70. 2007.

GUIDALLI, C. R. R. Diretrizes para o projeto de salas de aula em universidades visando ao bemestar do usuário. Dissertação (Mestrado) Programa de Pós-Graduação em Arquitetura, Universidade Federal de Santa Catarina, Florianópolis, 2012.

KAPLAN, S. Perception and landscape: conceptions and misconceptions. In: NASAR, J. L. (Ed.). Environmental aesthetics: theory, research, \& application. New York: Cambridge University Press, 1988. p. 45-55.

KAPLAN, S., KAPLAN, R. The experience of nature: A psychological perspective. New York: Cambridge University Press, 1989.

\section{Cognition and environment:}

Functioning in an uncertain world. New York: Praeger, 1982.

MARCONI, M. A.; LAKATOS, E. M. Técnicas de pesquisa: planejamento e execução de pesquisas, amostragens e técnicas de pesquisas, elaboração, 
análise e interpretação de dados. 5. ed. São Paulo: Atlas, 2002.

MORAES, A; MONT’ALVÃO, C. Ergonomia: conceitos e aplicações. 4. ed. ampliada. Rio de Janeiro: 2AB, 2009.

NASAR, J. L. Visual quality by design. Michigan: Haworth, Inc., 2008.

The evaluative image of places. In

$\overline{\text { WALSH}}$, W. B.; CRAIK, K. H.; PRINCE, R. H. 2nd ed. (Eds.). Person-environment psychology: new directions and perspectives. New Jersey: Lawrence Erlbaum Associates, 2000. p. 117-168.

The effect of sign complexity and coherence on the perceived quality of retail scenes. In NASAR, J. L. (Ed.). Environmental Aesthetics: theory, research, \& applications. New York: Cambridge University Press, 1988. p. 300-320.

ROAZZI, A.; MONTEIRO, C. M. G.; RULLO, G. Residential satisfaction and place attachment: A cross-cultural investigation. In COHEN, A. (Ed.). Facet Theory and scaling: In search of structure in behavioral and social sciences. Israel: Rubin R. I. D, 2009. p. 81-97.

RUSSEL, J. Affective appraisals of environments. In NASAR, J. L. (Ed.). Environmental aesthetics: theory, research, \& application. New York:

Cambridge University Press, 1988. p. 120-129.

RYKWERT, J. A sedução do lugar: a história e o futuro da cidade. São Paulo: Martins Fontes, 2004.

\section{SANOFF, H. School building assessment}

methods. 2001. Disponível em:

$<$ http://www.edfacilities.org/pubs/sanoffassess.pdf $>$. Acesso em: 05 out. 2018.

SHYE, S.; ELIZUR, D.; HOFFMAN, M.

Introduction to Facet Theory: content design and intrinsic data analysis in behavioral research.

London: Sage Publications, 1994.

SOLOMON, E. Guest Editors' Introduction Facet Theory in Organizational Research. International Studies of Management \& Organization, London, v. 49, n. 3, p. 233-246, 2019.
VILLAROUCO, V. Tratando de ambientes ergonomicamente adequados: seriam ergoambientes? In MONT'ALVÃO, C; VILLAROUCO, V. (Orgs.). Um novo olhar sobre o projeto: a ergonomia do ambiente construído. Teresópolis: 2AB, 2011. p. 25-46.

WARD, L., \& RUSSELL, J. The psychological representation of molar environments. Journal of Experimental Psychology: General, Washington DC, 110, p 121-152, 1981.

WOHWILL, J. Environmental aesthetics: The environment as a source of affect. In: ALTMANN, I., \& WOHWILL, J. F. (Eds.), Human Behaviour and the Environment: Advances in theory and research, V. p 37-861, New York: Plenum, 1976. 